\title{
Reproducing Abnormal Cholesterol Biosynthesis as Seen in the Smith-Lemli- Opitz Syndrome by Inhibiting the Conversion of 7-Dehydrocholesterol to Cholesterol in Rats
}

\author{
Guorong Xu, ${ }^{\star \star}$ Gerald Salen, ${ }^{\star *}$ Sarah Shefer, ${ }^{\star}$ Gene C. Ness, ${ }^{5}$ Thomas S. Chen, ${ }^{*}$ Zhihong Zhao, ${ }^{\mathbf{5}}$ and G. Stephen Tint ${ }^{\star *}$ \\ ${ }^{*}$ Department of Veterans Affairs Medical Center, East Orange, New Jersey 07018; ${ }^{\ddagger}$ Department of Medicine, University of Medicine \\ and Dentistry of New Jersey, New Jersey Medical School, Newark, New Jersey 07103; and 'Department of Biochemistry and Molecular \\ Biology and the Institute of Biomolecular Science, College of Medicine, University of South Florida, Tampa, Florida 33612-4799.
}

\begin{abstract}
The Smith-Lemli-Opitz syndrome is a recessive inherited disorder characterized by neurologic developmental defects and dysmorphic features in many organs. Recently, abnormal cholesterol biosynthesis with impaired conversion of 7-dehydrocholesterol to cholesterol has been discovered in homozygotes. To reproduce the biochemical abnormality, BM 15.766, a competitive inhibitor of 7-dehydrocholesterol$\Delta^{7}$-reductase, the enzyme that catalyzes the conversion of 7-dehydrocholesterol into cholesterol was fed by gavage to rats. After $14 \mathrm{~d}$, plasma cholesterol concentrations declined from $48 \mathrm{mg} / \mathrm{dl}$ to $16 \mathrm{mg} / \mathrm{dl}$ and 7-dehydro-cholesterol levels rose from trace to $17 \mathrm{mg} / \mathrm{dl}$. Hepatocytes surrounding the central vein developed balloon necrosis. Stimulating cholesterol synthesis with cholestyramine followed by BM 15.766 produced an additional $40 \%$ decline $(P<0.05)$ in plasma cholesterol and $34 \%$ increase in 7-dehydrocholesterol levels compared to the inhibitor alone. Adding 2\% cholesterol to the diet during the second week of BM 15.766 treatment increased plasma cholesterol threefold and decreased 7-dehydrocholesterol concentrations 55\%. Hepatic 3-hydroxy-3methylglutaryl co-enzyme A (HMG-CoA) reductase activity increased $73 \%$ with a 3.9-fold rise in mRNA levels but cholesterol $7 \alpha$-hydroxylase activity decreased slightly though mRNA levels increased 1.4 times with BM 15.766 treatment. These results demonstrate that BM 15.766 is a potent inhibitor of 7-dehydrocholesterol- $\Delta^{7}$-reductase. The model reproduces abnormal cholesterol biosynthesis as seen in the Smith-Lemli-Opitz syndrome and is useful to test different treatment strategies. Stimulating early steps of cholesterol synthesis worsens the biochemical abnormalities while feeding cholesterol inhibits abnormal synthesis, improves the biochemical abnormalities and prevents liver damage. ( $J$. Clin. Invest. 1995. 95:76-81.) Key words: Disease model, animal • fetal growth retardation - lipid metabolism, inborn errors • HMG-CoA reductase • Cholesterol $7 \alpha$-hydroxylase
\end{abstract}

\section{Introduction}

The Smith-Lemli-Opitz syndrome is an autosomal recessive disorder characterized by severe mental retardation with neuro-

Address correspondence to Dr. Guorong Xu, GI Lab (15A), VA Medical Center, 385 Tremont Ave., East Orange, NJ 07018-1095.

Received for publication 10 December 1993 and in revised form 27 June 1994

The Journal of Clinical Investigation, Inc.

Volume 95, January 1995, 76-81 logic dysfunction, failure to thrive, and distinctive dysmorphic features, that was first described in 1964 (1). The most prominent clinical manifestations include microcephaly, micrognathia, wide spread eyes, cataracts, flat nares, low set posteriorly rotated ears, and syndactyl. The prevalence of homozygotes is about 1 in 20,000 births (2) with an estimated carrier frequency of 1 to $2 \%$ (3)

Recently, we reported that homozygotes with the SmithLemli-Opitz syndrome show abnormal cholesterol biosynthesis with extremely low cholesterol levels and the accumulation of the cholesterol precursor, 7-dehydrocholesterol, and two related dehydrocholesterol isomers in plasma and tissues (4). The biochemical abnormalities probably result from incomplete conversion of the cholesterol precursor, 7-dehydrocholesterol to cholesterol suggesting that the microsomal enzyme which catalyzes this reaction, 7-dehydrocholesterol- $\Delta^{7}$-reductase is abnormal (Fig. 1).

In 1986, Pill and colleagues reported that BM 15.766, a synthetic piperazine derivative, inhibited the conversion of 7 dehydrocholesterol to cholesterol in cultured rat hepatocytes (5) and in rats (6). Other inhibitors of cholesterol synthesis such as AY-9944, trans-1,4-bis(2-dichlorobenzylaminomethyl) cyclohexane dihydrochloride (7) which also blocks 7-dehydrocholesterol- $\Delta^{7}$-reductase and triparanol, 1-[ $p$-(2-diethylaminoethoxy)-phenyl]-1-( $p$-tolyl $)-2-(p$-chlorophenyl $)$ ethanol, an inhibitor of desmosterol-24-reductase (8), when fed to pregnant animals, may produce severe congenital abnormalies in their offspring. (9-11). Some of the congenital defects resemble those found in homozygotes with the Smith-Lemli-Opitz syndrome and suggest that defects in cholesterol synthesis are capable of producing congenital abnormalies common to the phenotype. In this paper, we describe the effects of BM 15.766 on cholesterol and bile acid metabolism in rats and demonstrate that inhibition of 7-dehydrocholesterol- $\Delta^{7}$-reductase reproduces the biochemical abnormalities found in homozygotes with the Smith-Lemli-Opitz syndrome. The effect of cholesterol feeding and bile acid malabsorption was also evaluated in the BM 15.766-treated rats.

\section{Methods}

\section{Chemicals}

BM 15.766, 4-(2-[1-(4-chlorocinnamyl)piperazin-4-yl] ethyl)-benzoic acid was a gift from Boehringer Mannheim GmbH (Mannheim, Germany). 7-Dehydrocholesterol (5,7-cholestdien-3 $\beta$-ol) was purchased from Aldrich Chemical Company, Inc. (Milwaukee, WI) and cholesterol (5-cholesten-3 $\beta$-ol) was obtained from Sigma Chemical Co. (St. Louis, MO).

Experimental plan

28 male Spraque-Dawley rats from Charles River Laboratories (Wilmington, MA) weighing 300-350 g were housed individually, and were 


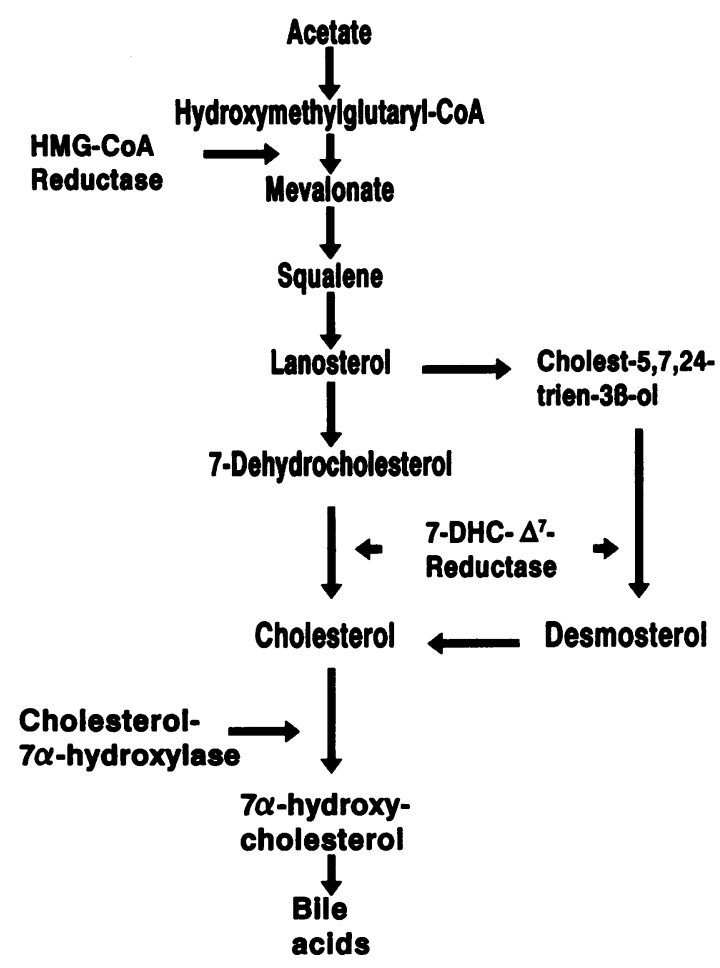

Figure 1. Diagram of cholesterol and bile acid synthetic pathways showing the location of the key rate-controlling steps catalyzed by HMGCoA reductase (for cholesterol synthesis) and cholesterol $7 \alpha$-hydroxylase (for bile acid synthesis). The conversion of 7-dehydrocholesterol to cholesterol is catalyzed by 7-dehydrocholesterol(DHC)- $\Delta^{7}$-reductase and is blocked in homozygotes with the Smith-Lemli-Opitz syndrome.

divided into six treatment groups: group $1(n=6)$ was fed rat chow powder and $1 \mathrm{ml} 1 \%$ xylose (XYLO.PFAN; Adria Laboratories, Columbus, $\mathrm{OH}$ ) solution/day by gavage and served as control; group 2 ( $n$ =3) was fed rat chow powder plus BM 15.766 (30 mg/kg per day) suspended in aqueous $1 \%$ xylose $(1 \mathrm{ml} / \mathrm{d})$ given by gavage for $3 \mathrm{~d}$; group $3(n=9)$ was fed rat chow powder plus BM 15.766 for 2 wk; group $4(n=8)$ was fed rat chow powder plus BM 15.766 for 2 wk after which the inhibitor was discontinued and the rats were fed only chow powder for another 2 wk; group $5(n=3)$ was fed rat chow powder plus BM 15.766 for 2 wk with 2\% cholesterol added to the diet during the second week. Group $6(n=3)$ was fed rat chow powder mixed with $2.5 \%$ Cholestyramine (Merck, Rahway, NJ) for $7 \mathrm{~d}$ combined with BM 15.766 for the last $3 \mathrm{~d}$, since this combination produced toxicity if continued for more than $1 \mathrm{wk}$. At the completion of the experiment, bile fistulas were constructed in each rat and bile was drained for $30 \mathrm{~min}$ to obtain the hepatic bile acid flux, after which the animals were sacrificed and blood and liver were obtained for sterol and hepatic enzyme activity and mRNA level determinations. The inhibitor was fed at 10 a.m. each day and the animals were killed around 2 p.m., the low point in the diurnal cholesterol and bile acid synthetic cycles. The experiment protocol was approved by the committees on animal studies at VA Medical Center (East Orange, NJ) and University of Medicine and Dentistry of New Jersey-New Jersey Medical School (Newark, NJ).

\section{Chemical analysis}

Assays for bile acids and sterols. Bile acids were extracted from the bile $(100 \mu \mathrm{l})$ and deconjugated and methylated as described previously (12). Trimethylsilyl ether derivatives were prepared and bile acids were quantitated by capillary gas-liquid chromatograghy on a Hewlett-Pack- ard model 5890A (Hewlett-Packard, Palo Alto, CA) equipped with a 25-m fused silica CP-Sil 5-CB capillary column (7).

Neutral sterols were extracted with hexane from $1 \mathrm{ml}$ plasma or 0.5 $\mathrm{ml}$ bile after saponification in $1 \mathrm{~N}$ ethanolic $\mathrm{NaOH}$. Trimethylsilyl ether derivatives were prepared and quantitated by capillary gas-liquid chromatography as described previously (13). The retention times of the sterol trimethylsilyi ethers relative to the internal standard, $5 \alpha$-cholestane (retention time $15.21 \mathrm{~min}$ ) were: cholesterol, 1.41 and 7-dehydrocholesterol, 1.48.

Assays for hepatic microsomal total 3-hydroxy-3-methylglutaryl coenzyme A (HMG-CoA) reductase and cholesterol $7 \alpha$-hydroxylase activities. Hepatic microsomes were prepared by differential ultracentrifugation (14), and the protein determined according to Lowry et al. (15). The assay for HMG-CoA reductase activity was based on the methods by George et al. (16) and Nguyen et al. (17). Briefly, 50-200 $\mu \mathrm{g}$ of microsomal protein was preincubated at $37^{\circ} \mathrm{C}$ for $5 \mathrm{~min}$ in a final volume of $150 \mu \mathrm{l}$ buffer ( $50 \mathrm{mM} \mathrm{K}_{2} \mathrm{HPO}_{4}, 30 \mathrm{mM}$ EDTA, $10 \mathrm{mM}$ DTT, 70 $\mathrm{mM} \mathrm{KCl}, \mathrm{pH} 7.4$ ) containing a NADPH generating system (34 mM $\mathrm{NADP}^{+}, 30 \mathrm{mM}$ glucose-6-phosphate, $0.3 \mathrm{U}$ glucose-6-phosphate dehydrogenase ) and $\left[{ }^{3} \mathrm{H}\right]$ mevalonolactone $(40,000 \mathrm{dpm})$ as internal recovery standard. The reaction was started with the addition of $30 \mathrm{nmol} \mathrm{[3-}$ ${ }^{14} \mathrm{C}$ ]HMG-CoA (Amersham Corp., Arlington Heights, IL; specific activity, $30 \mathrm{dpm} / \mathrm{pmol}$ ) and stopped after $15 \mathrm{~min}$ at $37^{\circ} \mathrm{C}$ with the addition of $20 \mu \mathrm{l} 6 \mathrm{~N} \mathrm{HCl}$. Zero-time controls were run with each experiment. After lactonization at $37^{\circ} \mathrm{C}$ for $30 \mathrm{~min}$, the products were separated by thin-layer chromatography, and mevalonolactone quantitated by liquid scintillation counting (17).

Cholesterol $7 \alpha$-hydroxylase activity was measured in hepatic microsomes by the isotope incorporation method of Shefer et al. (14).

Isolation and quantitation of $m R N A$. Total RNA from samples of frozen liver was isolated by the acid guanidinium thiocyanate-phenolchloroform extraction method (18). Portions of frozen liver, $0.2 \mathrm{~g}$, were homogenized in $2 \mathrm{ml}$ of room temperature TRI Reagent purchased from Molecular Research Center, Cincinnati, Ohio, using a Polytron Tissue Disrupter at full speed for 5-10 s. After $5 \mathrm{~min}, 0.4 \mathrm{ml}$ of chloroform was added, the sample mixed vigorously and centrifuged at $12,000 \mathrm{~g}$ for $15 \mathrm{~min}$ at $4^{\circ} \mathrm{C}$. The aqueous phase was removed and $1 \mathrm{ml}$ of isopropanol was added. The samples were mixed and allowed to stand at room temperature for 5-10 min, then centrifuged at $12,000 \mathrm{~g}$ for $10 \mathrm{~min}$ at $4^{\circ} \mathrm{C}$. The pelleted RNA was then washed in $75 \%$ ethanol. The total RNA pellet was dissolved in $100 \mu \mathrm{l}$ of diethylpyrocarbonate treated water. Poly (A) ${ }^{+}$RNA was isolated by oligo (dT) cellulose chromatography (19). The relative levels of HMG-CoA reductase and cholesterol $7 \alpha$-hydroxylase mRNA were quantitated by Northern blotting analysis as previously described (20) except that a Red Roller hybridization oven from Hoefer Scientific Instruments was used. $\beta$-Actin was served as the internal standard. The cDNAs for hamster HMG-CoA reductase, pRED 227 and human $\beta$-actin, $\mathrm{HHCl} 89$ were purchased from American Type Culture collection (Rockville, MD). The cDNA for rat liver cholesterol $7 \alpha$-hydroxylase, $7 \alpha 6$, was a gift from Dr. J. Y. L. Chiang (Northeastern Ohio University, Rootstown, $\mathrm{OH}$ ).

\section{Statistical study}

Data were analyzed statistically using the unpaired Student's $t$ test.

\section{Results}

Measurements of plasma cholesterol and 7-dehydrocholesterol levels in rats treated with BM 15.766 are given in Table I. After $3 \mathrm{~d}$ of BM 15.766 feeding, plasma cholesterol concentrations declined $40 \%(P<0.05)$ and 7-dehydrocholesterol levels which were barely detected in untreated controls, increased markedly. Continuing the treatment for 2 wk resulted in a $67 \%$ decline for plasma cholesterol $(P<0.0001)$ and a further rise $(+60 \%)$ in 7-dehydrocholesterol levels. Discontinuation of the inhibitor for $2 \mathrm{wk}$ allowed plasma cholesterol concentrations to 
Table I. The Effect of BM 15.766 on Plasma Sterols

\begin{tabular}{lcc}
\hline & Cholesterol & 7-dehydrocholesterol \\
\hline & $m g / d l$ & $m g / d l$ \\
Controls $(n=6)$ & $48.1 \pm 6.0$ & Trace $^{\ddagger}$ \\
BM 15.766 3 d $(n=3)$ & $28.9 \pm 4.8$ & $10.7 \pm 1.7^{8}$ \\
BM 15.766 2 wk $(n=9)$ & $15.7 \pm 4.7$ & $17.0 \pm 3.4^{8}$ \\
BM 15.766 2 wk +2 wk no & & \\
treatment* $(n=8)$ & $52.4 \pm 6.2$ & Trace $^{\ddagger}$ \\
\hline
\end{tabular}

Data are expressed as mean \pm SD. * After 2 wk of BM 15.766 feeding, the treatment was discontinued for the following $2 \mathrm{wk}$. ${ }^{\ddagger}$ Trace amounts of 7-dehydrocholesterol, $<0.005 \mathrm{mg} / \mathrm{dl}$. ${ }^{8}$ Additional dehydrocholesterol (identified as 5,8-cholestadien-3 $\beta$-ol) identical to that designated as isomeric dehydrocholesterol I in the plasma of homozygotes with the Smith-Lemli-Opitz syndrome (reference 4) could be detected along with 7-dehydrocholesterol in the plasma of the rats treated with BM 15.766 .

recover to the pretreatment level at which time 7-dehydrocholesterol disappeared from the plasma.

The changes in biliary sterol and bile acid outputs during these treatment periods are listed in Table II. After 2 wk of feeding BM 15.766, biliary cholesterol secretion was reduced $53 \%(P<0.0001)$ with a marked increase of 7 -dehydrocholesterol, so that the precursor was 1.8 times more abundant than cholesterol in the bile. Discontinuing the inhibitor for $2 \mathrm{wk}$, restored biliary cholesterol outputs to normal levels and eliminated 7-dehydrocholesterol from the bile.

Total biliary bile acid outputs which represent the hepatic bile acid flux declined $18 \%(P<0.05)$ after 2 wk of BM 15.766. After the inhibitor was stopped for $2 \mathrm{wk}$, the biliary bile acid output rebounded $68 \%(P<0.0005)$ which was $37 \%$ greater $(P<0.05)$ than the bile acid output in the untreated rats (Table II). Cholic acid was the major biliary bile acid and accounted for $77 \pm 5 \%$ of the total bile acids. The proportion rose to $88 \pm 4 \%$ after 2 wk treatment with BM 15.766 and returned to pretreatment value after discontinuation of the inhibitor.

Figs. 2 and 3 show the changes in plasma cholesterol and 7-dehydrocholesterol concentrations in rats when either $2.5 \%$ cholestyramine or $2 \%$ cholesterol was added to the diet in combination with BM 15.766. When cholestyramine was given together with BM 15.766 (Fig. 2), plasma cholesterol levels de-

Table II. The Effect of BM 15.766 on Biliary Sterols and Bile Acid Output

\begin{tabular}{|c|c|c|c|}
\hline & \multicolumn{2}{|c|}{ Biliary sterols } & \multirow{2}{*}{$\begin{array}{l}\text { Biliary bile } \\
\text { acid }\end{array}$} \\
\hline & Cholesterol & 7-dehydrocholesterol & \\
\hline & & $\mu g / h$ & $m g / h$ \\
\hline Controls $(n=6)$ & $193 \pm 45$ & trace $^{\ddagger}$ & $14.8 \pm 1.3$ \\
\hline BM 15.7662 wk $(n=9)$ & $90 \pm 26$ & $249 \pm 69$ & $12.1 \pm 1.7$ \\
\hline $\begin{array}{c}\text { BM } 15.7662 \mathrm{wk}+2 \mathrm{wk} \\
\text { no treatment* }(n=4)\end{array}$ & $199 \pm 59$ & $\operatorname{trace}^{\ddagger}$ & $20.3 \pm 3.6$ \\
\hline
\end{tabular}

Data are expressed as mean \pm SD. * After 2 wk of BM 15.766 feeding, the treatment was discontinued for the following $2 \mathrm{wk}$. ${ }^{\ddagger}$ Trace amounts of 7-dehydrocholesterol, $<0.005 \mathrm{mg} / \mathrm{dl}$.

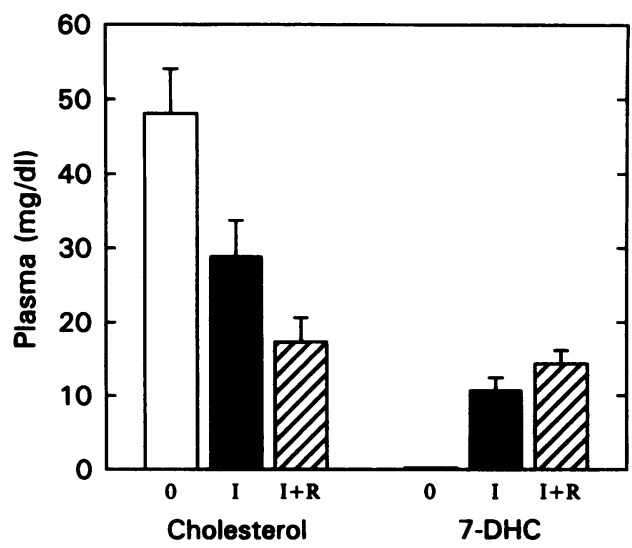

Figure 2. The effect of feeding $2.5 \%$ cholestyramine for $7 \mathrm{~d}$ and BM 15.766 in combination for the final $3 \mathrm{~d}$ on plasma cholesterol and 7dehydrocholesterol (7-DHC) concentrations in rats. I, BM 15.766 only; $I+R$, BM $15.766+$ Resin (cholestyramine); $O$, no treatment.

clined an additional 40\% $(P<0.05)$ and 7-dehydrocholesterol rose $34 \%$, as compared with levels after BM 15.766 feeding for $3 \mathrm{~d}$. In contrast, when $2 \%$ cholesterol was added to the diet during the second week of BM 15.766 feeding (Fig. 3), plasma cholesterol concentrations increased threefold $(P<0.0001)$, which was $20 \%$ above the control level while 7-dehydrocholesterol levels were reduced $50 \%(P<0.005)$ as compared with 2 wk of BM 15.766 feeding alone.

Activities for hepatic HMG-CoA reductase and cholesterol $7 \alpha$-hydroxylase, the respective rate-controlling enzymes for cholesterol and bile acid synthesis are reported in Table III. After 2 wk of BM 15.766 treatment, HMG-CoA reductase activity rose $73 \%(P<0.05)$ and remained elevated even after the inhibitor was discontinued for the following 2 wk. However, the administration of $2 \%$ cholesterol in chow during the second week of BM 15.766 treatment inhibited HMG-CoA reductase activity $75 \%(P<0.005)$ compared to BM 15.766 alone. In contrast, cholestyramine treatment for $7 \mathrm{~d}$ combined with BM 15.766 treatment for the final $3 \mathrm{~d}$ increased the activity 8.8 times $(P<0.0001)$.

Cholesterol $7 \alpha$-hydroxylase activity declined $13 \%$ (NS)

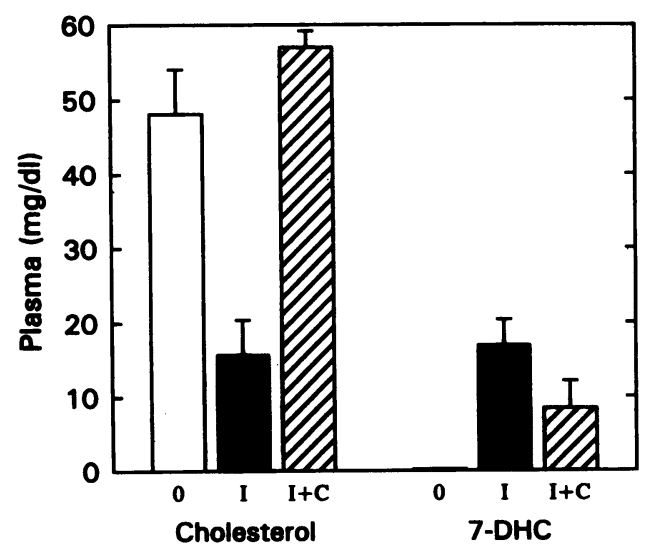

Figure 3 . The effect of feeding $2 \%$ cholesterol (during the second week) on plasma cholesterol and 7-dehydrocholesterol (7-DHC) concentrations in rats treated with BM 15.766 (for $2 \mathrm{wk}$ ). $I$, BM 15.766 only; $I$ $+C, \mathrm{BM} 15.766+$ Cholesterol; $O$, no treatment. 
Table III. The Effect of BM 15.766 on the Hepatic Total HMGCoA Reductase and Cholesterol $7 \alpha$-Hydroxylase Activities

\begin{tabular}{lcc}
\hline \multicolumn{1}{c}{ Treatment } & $\begin{array}{c}\text { HMG-CoA } \\
\text { reductase }\end{array}$ & $\begin{array}{c}\text { Cholesterol } \\
7 \alpha \text {-hydroxylase }\end{array}$ \\
\hline & pmolmg/min & $p$ molmg/min \\
Control $(n=6)$ & $53.4 \pm 9.4$ & $19.7 \pm 6.0$ \\
BM 15.766 2 wk $(n=9)$ & $92.4 \pm 33.5$ & $17.2 \pm 6.0$ \\
BM 15.766 2 wk + 2 wks no & & \\
$\quad$ treatment* $(n=4)$ & $100.5 \pm 35.7$ & $24.5 \pm 8.9$ \\
BM 15.766 2 wk +1 wk & & \\
$\quad$ Cholesterol ${ }^{\ddagger}(n=5)$ & $24.0 \pm 9.4$ & $22.9 \pm 3.1$ \\
BM 15.766 3 d $(n=3)$ & $33.5 \pm 8.4$ & $13.3 \pm 5.6$ \\
$\begin{array}{l}\text { Cholestyramine }+ \text { BM } 15.7663 \mathrm{~d}^{3} \\
\quad(n=3)\end{array}$ & $294.5 \pm 4.6$ & $30.7 \pm 8.9$ \\
\hline
\end{tabular}

* After 2 wk of BM 15.766 feeding, the treatment was discontinued for the following 2 wk. ${ }^{\ddagger} 2 \%$ cholesterol was added to the diet during the second week of the 2 wk BM 15.766 treatment. $2.5 \%$ cholestyramine was fed for $7 \mathrm{~d}$ combined with BM 15.766 feeding in the last $3 \mathrm{~d}$.

after 2 wk of BM 15.766 treatment but increased $42 \%$ after the inhibitor was discontinued for $2 \mathrm{wk}$. Adding 2\% cholesterol to the diet during the second week of BM 15.766 treatment increased the activity $33 \%$ (NS). When the inhibitor was combined with cholestyramine, cholesterol $7 \alpha$-hydroxylase activity rose 2.3 times compared with $3 \mathrm{~d}$ of inhibitor treatment alone $(P<0.05)$.

Figs. 4 and 5 and Table-IV show the effect of BM 15.766 on relative steady state mRNA levels of hepatic HMG-CoA reductase and cholesterol $7 \alpha$-hydroxlase respectively, as determined by Northern blot analysis and densitometric scanning and corrected for the recovery of $\beta$-actin mRNA. Relative steady state mRNA levels of both HMG-CoA reductase ( $P$ $<0.005)$ and cholesterol $7 \alpha$-hydroxylase $(P<0.001)$ were increased in rats treated with BM 15.766 for 2 weeks compared to the control rats and remained high 2 wk after BM 15.766 was withdrawn.

Fig. 6 shows the effect of 2 wk treatment of BM 15.766 on hepatic histology. Under light microscopy, the general architecture of the hepatic lobule was preserved, but hepatocytes around the central vein showed balloon degeneration. Electronmicroscopy revealed increased mitochondria and proliferation of the rough endoplasmic reticulum. Discontinuing the inhibitor for 2

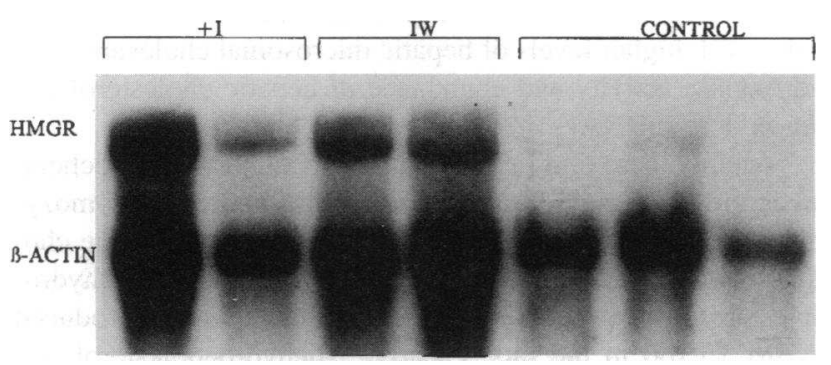

Figure 4. Northern blot analysis of rat hepatic HMG-CoA reductase $(H M G R)$ mRNA levels. After 2 wk treatment with BM $15.766(+I)$, mRNA levels of hepatic HMG-CoA reductase increase and remain higher after BM 15.766 has been withdrawn $(I W)$ for $2 w k$; $\beta$-actin mRNA serves as an internal standard.

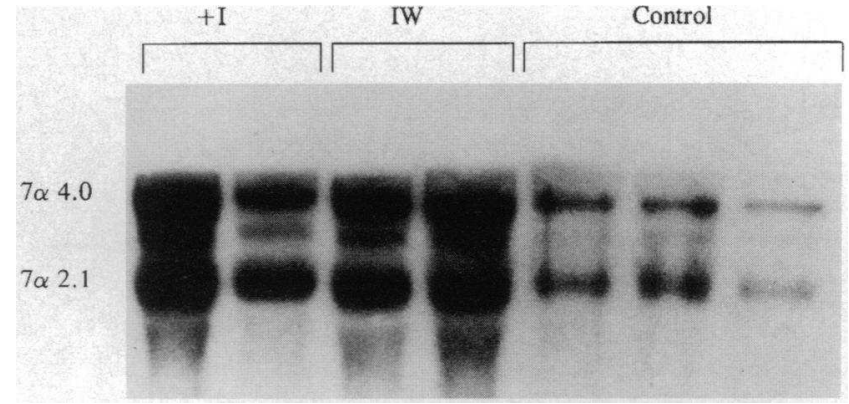

Figure 5. Northern blot analysis of rat hepatic cholesterol $7 \alpha$-hydroxylase mRNA levels $(7 \alpha)$. After 2 wk treatment with BM $15.766(+I)$, mRNA levels of hepatic cholesterol $7 \alpha$-hydroxylase increase and remain higher after BM 15.766 has been withdrawn (IW) for 2 wk. Three cholesterol $7 \alpha$-hydroxylase transcripts are noted at 4.0, 3.6 and $2.1 \mathrm{~kb}$.

wk restored normal liver histology although increased mitochondria and rough endoplasmic reticulum persisted (not shown).

\section{Discussion}

These results confirm that BM 15.766 is a potent inhibitor of cholesterol biosynthesis. By blocking 7-dehydrocholesterol$\Delta^{7}$-reductase (Fig. 1), BM 15.766 caused a marked reduction in plasma cholesterol levels associated with an enormous increase in the concentration of the cholesterol precursor, 7-dehydrocholesterol. Biliary cholesterol outputs also declined markedly with the excretion of 7-dehydrocholesterol enhanced so that the ratio of the precursor to cholesterol was 1.7 times greater in bile than in plasma. The elevated enrichment of 7-dehydrocholesterol relative to cholesterol in bile not only reflects the enzymatic block and inability of 7-dehydrocholesterol to be transformed to cholesterol but also suggests that 1.8 times more 7-dehydrocholesterol than cholesterol is produced since biliary sterol outputs probably mirror endogenous hepatic sterol synthesis. 2 wk after the inhibitor (BM 15.766) was discontinued, the cholesterol biosynthetic pathway had normalized: plasma cholesterol concentrations and biliary cholesterol outputs were restored and 7-dehydrocholesterol was eliminated from plasma and bile. This suggests that the inhibition of cholesterol biosynthesis by BM 15.766 is reversible and that newly formed 7 -

Table IV. The Effect of BM 15.766 on the Relative Hepatic HMGCoA Reductase and Cholesterol $7 \alpha$-hydroxylase mRNA Levels

\begin{tabular}{lcc}
\hline \multicolumn{1}{c}{ Treatment } & $\begin{array}{c}\text { HMG-CoA reductase } \\
\text { mRNA* }^{*}\end{array}$ & $\begin{array}{c}\text { Cholesterol } \\
7 \alpha \text {-hydroxylase } \\
\text { mRNA* }^{*}\end{array}$ \\
\hline Controls $(n=6)$ & $0.08 \pm 0.03$ & $0.46 \pm 0.26$ \\
BM 15.766 2 wk $(n=6)$ & $0.21 \pm 0.07^{\S}$ & $1.03 \pm 0.05^{\| \prime}$ \\
$\begin{array}{l}\text { BM 15.766 2 wk }+2 \mathrm{wk} \text { no } \\
\text { treatment }\end{array}{ }^{\ddagger}(n=6)$ & $0.18 \pm 0.03^{\| \prime}$ & $0.75 \pm 0.05$ \\
& & \\
\hline
\end{tabular}

* Corrected for the recovery of $\beta$-actin mRNA. ${ }^{\ddagger}$ After 2 wk of BM 15.766 feeding, the treatment was discontinued for the following $2 \mathrm{wk}$. ${ }^{8} P<0.005$ as compared with the relevant control value. " $P<0.001$ as compared with the relevant control value. 


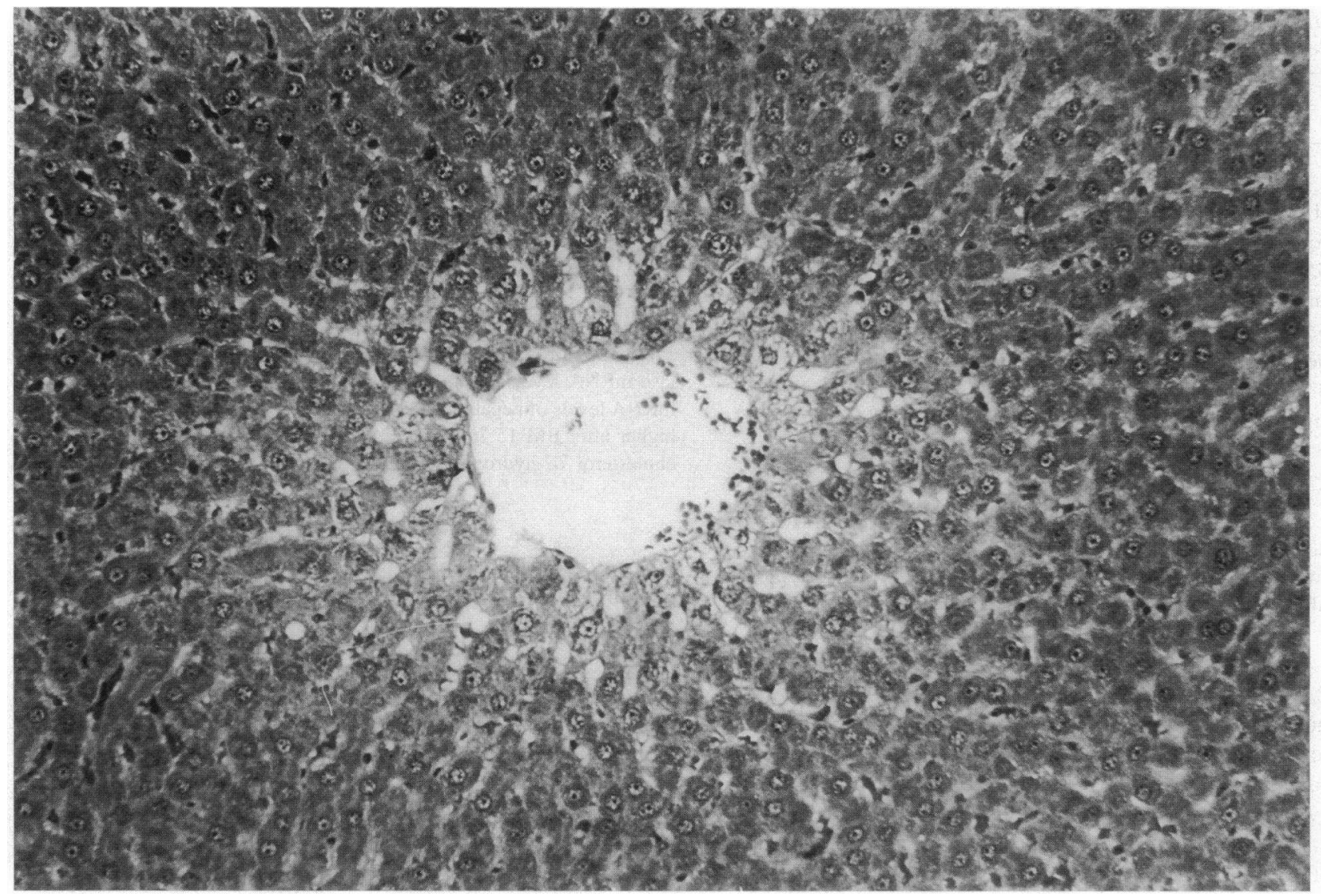

Figure 6. Photomicrograph of hepatic histology (hematoxylin and eosin stain) in rat treated with BM 15.766 for 2 wk. Hepatocytes around the central vein show balloon degeneration $(\times 200)$.

dehydrocholesterol- $\Delta^{7}$-reductase in the absence of the inhibitor is capable of transforming the accumulated 7-dehydrocholesterol to cholesterol. Interestingly, HMG-CoA reductase activity and mRNA levels remained stimulated probably by the need to replenish depleted tissue cholesterol pools. Similarly, when cholesterol is fed during treatment with BM 15.766, plasma cholesterol rose to pretreatment levels and 7-dehydrocholesterol concentrations declined substantially. Not only is dietary cholesterol absorbed to replace depleted plasma and tissue compartments, but the expanded cholesterol pool exerts negative feedback control on HMG-CoA reductase (Table III) reducing abnormal endogenous synthesis as evinced by the decrease in 7-dehydrocholesterol levels. Conversely, when HMG-CoA reductase was stimulated by pretreatment with cholestyramine, the biochemical abnormalities caused by BM 15.766 were worsened with further decreased cholesterol and increased 7 dehydrocholesterol levels in plasma (Fig. 2). The increased formation of the early precursor, mevalonic acid, which is the product of HMG-CoA and almost totally committed to the cholesterol biosynthetic pathway, mostly ended as 7-dehydrocholesterol in the BM 15.766 treated rats because of the inhibition of 7-dehydrocholesterol- $\Delta^{7}$-reductase.

After 2 wk of BM 15.766 treatment, HMG-CoA reductase activities and steady state mRNA levels were increased indicating up-regulation of early steps of the cholesterol biosynthetic pathway probably stimulated by the marked reduction in circulating plasma cholesterol and biliary bile acid pools. Clearly, the accumulated 7-dehydrocholesterol does not exert negative feedback regulation of HMG-CoA reductase.

The bile acid pool decreased as evidenced by the reduced hepatic bile acid flux during treatment with BM 15.766. The reduction in cholesterol $7 \alpha$-hydroxylase activity in combination with increased steady state mRNA levels suggests that the decreased cholesterol substrate supply and/or competitive inhibition of cholesterol $7 \alpha$-hydroxylase by the large microsomal pool of 7-dehydrocholesterol account for diminished formation of bile acids. 2 wk after BM 15.766 was discontinued, the hepatic bile acid flux was $30 \%$ higher than the pretreatment level (Table II) suggesting increased bile acid synthesis that was supported by the increased cholesterol supply, elimination of 7-dehydrocholesterol, higher levels of hepatic microsomal cholesterol $7 \alpha-$ hydroxylase activity and abundance of hepatic cholesterol $7 \alpha-$ hydroxylase mRNA.

Together these findings confirm the location of the biochemical abnormality in the Smith-Lemli-Opitz syndrome. Homozygotes with this syndrome show reduced plasma and tissue cholesterol concentrations associated with high levels of 7-dehydrocholesterol (4), precisely the biochemical findings produced by BM 15.766 in the rats. Clearly, 7-dehydrocholesterol- $\Delta^{7}$ reductase is abnormal in Smith-Lemli-Opitz homozygotes. Also the rat experiments where cholesterol was given with BM 15.766 suggest that cholesterol treatment of the homozygotes with Smith-Lemli-Opitz syndrome might be beneficial. The added absorbed cholesterol can replenish tissue pools and in- 
hibit HMG-CoA reductase to suppress the rate-controlling step of the abnormal pathway. Stimulating HMG-CoA reductase by feeding cholestyramine is counterproductive and would be expected to worsen the biochemical abnormalities by reducing cholesterol levels further and increasing the precursor concentrations, since the conversion of 7-dehydrocholesterol to cholesterol was blocked. Because bile acid synthesis is also compromised, treatment should also include bile acid replacement to expand the pool and facilitate cholesterol absorption and exert additional feedback inhibition of cholesterol synthesis (21).

In a preliminary report, Shefer et al. (22) showed that 7 dehydrocholesterol $-\Delta^{7}$-reductase activity in the liver of rats treated with BM 15.766 and of a homozygote with the SmithLemli-Opitz syndrome was reduced, as compared with the control values. Thus, reduced 7-dehydrocholesterol- $\Delta^{7}$-reductase activity, which was competitively blocked in rats treated with BM 15.766 and is inheritedly abnormal in the Smith-LemliOpitz syndrome, is responsible for the biochemical abnormalities in this disease.

The absence of desmosterol (5,24-cholestadien-3 $\beta$-ol) or other C-24 unsaturated sterols in the plasma and bile of the BM 15.766 treated rats indicated that the function of $\Delta^{24}$ reductase is not affected by inhibition of 7-dehydrocholesterol- $\Delta^{7}$-reductase. The double bond in the side chain at C-24 can be reduced easily and all desmosterol intermediates transferred to the 7dehydrocholesterol pathway. In addition, the deficiency of cholesterol in BM 15.766-treated animals and patients with the Smith-Lemli-Opitz syndrome strongly indicates that the desmosterol pathway is not separate from the pathway through which 7-dehydrocholesterol is used and can not produce cholesterol independently when the $\Delta^{7}$ reductase is blocked. (Fig. 1)

In summary, BM 15.766 is a powerful inhibitor of 7-dehydrocholesterol- $\Delta^{7}$-reductase reproducing the biochemical defects of low plasma cholesterol with high 7-dehydrocholesterol levels, found in homozygotes with the Smith-Lemli-Opitz syndrome. Stimulating cholesterol synthesis with cholestyramine worsens the biochemical abnormalities while feeding cholesterol shuts down abnormal cholesterol synthesis and restores cholesterol in the plasma and tissues.

\section{Acknowledgments}

We thank Bibiana Pcolinsky, Susan Hauser, and Eva Paroulek for excellent technical assistance and Barbara Rouse for preparing the manuscript.

This study was supported by VA Research Service and US Public Health Service grants HL-17818, HL-18094, DK-18707, and DK-26756.

\section{References}

1. Smith, D. W., L. Lemli, and J. M. Opitz. 1964. A newly recognized syndrome of multiple congenital anomalies. J. Pediatr. 64:210-217.

2. Opitz, J. M., V. B. Penchaszadeh, M. C. Holt, and L. M. Spano. 1987. Smith-Lemli-Opitz (RSH) syndrome bibliography. Am. J. Med. Genet. 28:645750 .

3. Chasalow, F. I. 1985. Possible abnormalities of steroid secretion in children with Smith-Lemli-Opitz syndrome and their parents. Steroids. 46:827-843.

4. Tint, G. S., M. Irons, E. R. Elias, A. K. Batta, R. Frieden, T. S. Chen, and G. Salen. 1994. Defective cholesterol biosynthesis associated with the SmithLemli-Opitz syndrome. N. Engl. J. Med. 330:107-113.

5. Aufenanger, J., J. Pill, F. H. Schmidt, and K. Stegmeier. 1986. The effects of BM 15.766, An inhibitor of 7-dehydrocholesterol $\Delta^{7}$-reductase, on cholestero biosynthesis in primary rat hepatocytes. Biochem. Pharmacol. 35:911-916.

6. Pill, J., F. H. Schmidt, K. Stegmeier, and E. C. Witte. 1985. Effects of BM 15.766 on serum lipids in rats. Horm. Metabol. Res. 17:543-544.

7. Dvornik, D., M. Kraml, J. Dubuc, M. Givner, and R. Gaudry. 1963. A novel mode of inhibition of cholesterol biosynthesis. J. Am. Chem. Soc. 85:3309.

8. Steinberg, D., and J. Avigan. 1960. Studies of cholesterol biosynthesis. II The role of des mosterol in the biosynthesis of cholesterol. J. Biol. Chem. 235:3127-3129.

9. Roux, C. 1964. Action tratogne du triparanol chez l'animal. Arch. Fr. Pediatr. 21:451-464.

10. Roux, C., and M. Aubry. 1966. Action tratogne chez le rat d'un inhibiteur de la synthse du cholestrol, le AY 9944. C. R. Soc. Biol. 160:1353-1357.

11. Roux, C., R. Dupuis, C. Horvath, and J.-N. Talbot. 1980. Teratogenic effect of an inhibitor of cholesterol synthesis (AY 9944) in rats: correlation with maternal cholesterolemia. J. Nutr. 110:2310-2312.

12. Xu, G., G. Salen, S. Shefer, A. K. Batta, G. C. Ness, L. B. Nguyen, Z. Zhao, T. S. Chen, W. Niemann, and G. S. Tint. 1993. Different feedback regulation of hepatic cholesterol and bile acid synthesis by glycodeoxycholic acid in rabbits. Gastroenterology. 105:1192-1199.

13. Nguyen, L. B., S. Shefer, G. Salen, I. Horak, G. S. Tint, and D. J. McNamara. 1988. The effect of abnormal plasma and cellular sterol content and composition on low density lipoprotein uptake and degradation by monocytes and lymphocytes in sitosterolemia with xanthomatosis. Metab. Clin. Exp. 37:346351 .

14. Shefer, S., G. Salen, and A. K. Batta. 1986. Methods of assay. In Cholesterol $7 \alpha$-hydroxylase ( $7 \alpha$-monooxygenase). R. Fears and J. R. Sabine, editors. CRC Press/Florida, Boca Raton. 43-49.

15. Lowry, O. H., N. J. Rosebrough, A. L. Farr, and R. J. Randall. 1951. Protein measurement with the Folin phenol reagent. J. Biol. Chem. 193:265-275.

16. George, R., P. J. Davis, L. Luong, and N. J. Poznansky. 1990. Cholesterolmediated regulation of HMG-CoA reductase in microsomes from human skin fibroblasts and rat liver. Biochem. Cell Biol. 68:674-679.

17. Nguyen, L. B., S. Shefer, G. Salen, G. C. Ness, G. S. Tint, G. Zaki, and I. Rani. 1990. A molecular defect in hepatic cholesterol biosynthesis in sitosterolemia with xanthomato sis. J. Clin. Invest. 86:923-931.

18. Chomozynski, R., and N. Sacchi. 1987. Single step method of RNA isolation by acid guanidinium thiocyanate-phenol-chloroform extraction. Anal. Biochem. 162:156-159.

19. Aviv, N., and P. Ledder. 1972. Purification of biologically active globin mRNA by chromatography on oligothymidylic acid-cellulose. Proc. Natl. Acad. Sci. USA. 69:1408-1412.

20. Ness, G. C., R. K. Keller, and L. C. Pendelton. Feedback regulation of hepatic 3-hydroxy-3-methyl glutaryl coenzyme A reductase activity by dietary cholesterol is not due to altered mRNA levels. J. Biol. Chem. 266:14854-14857.

21. Shefer, S., L. B. Nguyen, G. Salen, G. C. Ness, I. R. Chowdhary, S. Lerner, A. K. Batta, and G. S. Tint. 1992. Differing effects of cholesterol and taurocholate on steady state hepatic HMG-CoA reductase and cholesterol $7 \alpha$ hydroxylase activities and mRNA levels in the rat. J. Lipid Res. 33:1193-1200.

22. Shefer, S., G. Salen, A. K. Batta, G. S. Tint, M. Irons, and E. R. Elias 1994. Reduced 7-dehydrocholesterol- $\Delta^{7}$-reductase activity in Smith-Lemli-Opitz syndrome. Am. J. Med. Genet. 50:336 (Abstr.) 